\title{
Mangrove Forest Classification in Drone Images Using HSV Color Moment and Haralick Features Extraction with K-Nearest Neighbor
}

\author{
Agus Wahyu Widodo ${ }^{\mathrm{a}, 1,{ }^{*}}$, Deo Hernando ${ }^{\mathrm{a}, 2}$, Wayan Firdaus Mahmudy ${ }^{\mathrm{a}, 3}$ \\ a Department of Computer Science, Universitas Brawijaya, Malang, Indonesia \\ 1'a_wahyu_w@ub.ac.id *; ${ }^{2}$ deodeo@student.ub.ac.id; ${ }^{3}$ wayanfm@ub.ac.id \\ * corresponding author
}

ARTICLE INFO

Article history

Received October 4, 2019

Revised October 23, 2019

Accepted November 22, 2019

Keywords

Mangrove Forest Classification

Haralick Features

HSV Color Moment

K-Nearest Neighbor

Drone Image

\begin{abstract}
Due to the problems with uncontrolled changes in mangrove forests, a forest function management and supervision is required. The form of mangrove forest management carried out in this study is to measure the area of mangrove forests by observing the forests using drones or crewless aircraft. Drones are used to take photos because they can capture vast mangrove forests with high resolution. The drone was flown over above the mangrove forest and took several photos. The method used in this study is extracting color features using mean values, standard deviations, and skewness in the HSV color space and texture feature extraction with Haralick features. The classification method used is the k-nearest neighbor method. This study conducted three tests, namely testing the accuracy of the system, testing the distance method used in the k-nearest neighbor classification method, and testing the k value. Based on the results of the three tests above, three conclusions obtained. The first conclusion is that the classification system produces an accuracy of $84 \%$. The second conclusion is that the distance method used in the knearest neighbor classification method influences the accuracy of the system. The distance method that produces the highest accuracy is the Euclidean distance method with an accuracy of $84 \%$. The third conclusion is that the $\mathrm{k}$ value used in the k-nearest neighbor classification method influences the accuracy of the system. The $\mathrm{k}$-value that produces the highest accuracy is $\mathrm{k}=3$, with an accuracy of $84 \%$.
\end{abstract}

This is an open access article under the $\mathrm{CC}-\mathrm{BY}-\mathrm{SA}$ license.

\section{Introduction}

There are problems with changes in forest area uncontrolled mangrove. Sometimes people cut down mangrove forests and converted it into aquaculture, agriculture or development projects [1]. Some caused by natural disasters, anthropogenic forces, and uncontrolled population growth [2]. On the other hand, mangrove forests provide habitat for several species of mammals, birds, crustaceans, fish, and others. Apart from being an animal habitat, mangroves can reduce the impact of sea waves, tsunamis, and wind erosion [3]. At other side, there is a large amount of carbon released to atmosphere due to mangrove deforestation. The need for management and supervision of this mangrove forest in maintaining the function of the mangrove forest and can be used to estimating carbon stocks [4] [5].

The importance of this research is to help classify mangroves so that they can be processed for mangrove forest management such as the calculation of mangrove forest area, monitoring forest activity, preventing deforestation or improper use of mangrove forests, and calculating carbon stocks. 
The form of mangrove forest management carried out in this study is to measure the area of mangrove forests. Because mangroves do not only consist of mangrove trees but also land and water areas, it is necessary to calculate the mangrove area only to get a more accurate area value. Besides, distinguishing between the extent of natural mangrove forests and mangrove forests planted helps researchers to measure the success of mangrove planting.

The research conducted was to observe mangrove forests using drones or crewless aircraft. The drone was flown over above the mangrove forest and took several photos. Photos taken will be used as data to calculate the area of mangrove forests [6]. In one photo, the area of natural mangroves, mangroves from planting, land areas, and water areas will be calculated. Drones are used to take photos because they can capture vast mangrove forests with high resolution [7]. Drones are more widely used than humans because of the cost of drones and time is more efficient than humans [8].

This system was created to assist researchers in measuring the area of mangrove forests in the images taken. The system can classify natural mangrove forests, planted mangrove forests, land areas, and water areas. One image will be classified for each part so that it can be distinguished between natural mangrove forests, mangrove forests as a result of planting, land areas, and water areas. To classify drone images taken automatically, an introduction to the characteristics of mangrove forests is needed. There needs to be a distinction between natural mangrove forests, mangroves from planting, land areas, and water areas. Characteristics that can be used as differentiators are color, shape, and texture characters [9] [10].

In previous studies, suitable color characteristics used for representation in forest imagery were HSV (Hue, Saturation, Value). The Hue value is a pure color value and is represented in numbers from 0 to 360, the Saturation value is a value that shows the percentage of gray colors in the image and is represented in decimal numbers from 0 to 1 , and the Value is the brightness value in the image and presented in numbers decimal 0 to 1 [11]. Color characteristics have three parameters that can be used namely mean, standard deviation, and skewness. In addition to the color characteristics, texture characteristics can also be used. One method that can be used is Haralick features. In previous studies, the texture characteristics of Haralick features were used to extract features in high-resolution satellite imagery. This study resulted in an accuracy rate of $93.29 \%$ [12].

In addition to extracting the values of color and texture features, classification is also needed. There are several classification methods, such as K-nearest Neighbor, Support Vector Machine (SVM), Naive Bayes, and others [13]. Based on previous research, the k-nearest neighbor method is a method that has a high level of time efficiency and uses less memory [14]. Also, the k-nearest neighbor method produces higher accuracy values compared to the SVM method in the classification using Haralick's texture features based on previous research [12].

Based on the needs of management and supervision of mangrove forest areas and previous studies, this study makes an application that can classify mangrove trees from drone images using HSV color features and Haralick texture features with the k-nearest neighbor classification method.

\section{Related Work}

There are several previous studies relating to the feature extraction method and the classification method used in this study. These studies are used as a reference in solving problems in this study.

The first study is research on the introduction of image developments of chicken embryo by using GLCM texture features with k-nearest neighbor method. This study classifies the images of chicken embryo development. This study uses GLCM as features. To extract texture features, this study uses GLCM. GLCM is made by using 4 different angular directions, namely $0^{\circ}, 45^{\circ}, 90^{\circ}$ and $135^{\circ}$. The features extracted from the GLCM matrix are features of homogeneity, contrast, correlation, energy, and entropy. The classification method used in this study is k-nearest neighbor using the Euclidean. The results obtained from this study were the highest accuracy of $93.33 \%$ [15].

The second study is a study of the effect of color models on the performance of Content-based Image Retrieval (CBIR) systems based on color moments. This study focuses on measuring the effect of taking color moment values on different color spaces in images to accuracy. This study uses the mean color features, standard deviations, and skewness in the HSV color space. This study conducted three tests on different color spaces, namely the HSV color space, the RGB color space, and the 
combined RGB and HSV color space. The best results obtained from these tests are the accuracy of $91 \%$ in the HSV color space testing. The combined color space of RGB and HSV produces an accuracy of $90 \%$, and the RGB color space produces an accuracy of $88 \%$ [16].

The third research is research on the classification of satellite images using SVM classification methods. This study classifies objects captured on satellites. This study uses the color features and texture features of Haralick. Haralick texture features used are features of homogeneity, contrast, correlation, local homogeneity, and entropy. This study conducted several tests to measure the effect of color features and texture features on accuracy. The best results were obtained in tests using color features and texture features with an accuracy of $93.68 \%$. Meanwhile, using only the color feature, the accuracy obtained is $83.19 \%$ and by using the texture feature only, the accuracy obtained is $87.27 \%$ [17].

The fourth study is a study of the diagnosis of glaucoma eye disease using Haralick's texture features. This study uses the retinal eye image to diagnose glaucoma. The retinal image can determine whether the patient has glaucoma or not. The feature used in this study is the Haralick texture feature, which consists of 14 features. These features are the angular second moment, contrast, correlation, sum of squares, inverse difference moment, sum average, sum variance, sum entropy, entropy, difference variance, difference entropy, information of correlation, and maximum correlation coefficient. The classification method used is a k-nearest neighbor. The results obtained from this study are accuracy above $98 \%$ in diagnosing retinal eye images [18].

Based on the four previous studies, the exact texture feature extraction method used for classification in satellite imagery is Haralick as evidenced by the fourth study. Meanwhile, the most appropriate color feature is the HSV color moment as evidenced by the second study. Then, the appropriate classification method used is the k-nearest neighbor method by comparing the level of accuracy in the third and fourth studies. The details of researches used on this paper can be seen in Table 1.

Table 1. Related Studies

\begin{tabular}{|c|c|c|c|c|}
\hline \multirow{2}{*}{ Studies } & \multicolumn{2}{|c|}{ Features Extraction } & \multirow{2}{*}{$\begin{array}{l}\text { Classification } \\
\text { Method }\end{array}$} & \multirow{2}{*}{ Accuracy } \\
\hline & Color & Texture & & \\
\hline $\begin{array}{l}\text { Combination of GLCM and KNN } \\
\text { Classification for Chicken Embryo } \\
\text { Development Recognition }\end{array}$ & - & GLCM & $\mathrm{KNN}$ & $93,33 \%$ \\
\hline $\begin{array}{l}\text { The Influence of the Color Model on the } \\
\text { Performance of a CBIR System Based on } \\
\text { Color Moments }\end{array}$ & $\begin{array}{c}\text { HSV Color } \\
\text { Moment }\end{array}$ & - & KNN & $91 \%$ \\
\hline $\begin{array}{c}\text { SVM and Haralick Features for Classification } \\
\text { of High-Resolution Satellite Images from } \\
\text { Urban Areas }\end{array}$ & $\begin{array}{l}\text { Color } \\
\text { channel }\end{array}$ & Haralick & SVM & $93,68 \%$ \\
\hline $\begin{array}{c}\text { Automated Diagnosis of Glaucoma using } \\
\text { Haralick Texture Features }\end{array}$ & - & Haralick & $\mathrm{KNN}$ & $>98 \%$ \\
\hline
\end{tabular}

\section{Method}

\subsection{HSV Color Moment Feature Extraction}

Color features are an essential feature of images because colors can be seen visually by the human eye [18] [19]. The color feature has three parameters that can be used for value extraction, which are mean, standard deviation, and skewness. One technique that can be used to extract color feature values is to use a color histogram. Color histograms often have noise values that reduce accuracy, so a color moment technique is needed to overcome them [20].

The Hue value is a true color value. Numbers from 0 to 360 and is the number to represent it. The Saturation value is a value that shows the percentage of gray colors in the image and is represented in decimal numbers from 0 to 1 . Moreover, the Value is the brightness value in the image and presented 
in numbers decimal 0 to 1 [21]. The formula to calculate the Hue value can be seen in Equation 1 [22] [23].

$$
\text { Hue }=\left\{\begin{array}{c}
0, \text { if Max }=\text { Min } \\
\frac{60^{\circ} * \frac{(G-B)}{(\text { Max }- \text { Min })}+0^{\circ}}{360}, \text { if Max }=R \text { and } G \geq B \\
\frac{60^{\circ} \frac{(G-B)}{(\text { Max }- \text { Min })}+360^{\circ}}{360}, \text { if Max }=R \text { and } G<B \\
\frac{60^{\circ} * \frac{(B-R)}{(\text { Max }- \text { Min })}+120^{\circ}}{360}, \text { jika Max }=G \\
\frac{60^{\circ} * \frac{(R-G)}{(\text { Max }- \text { Min })}+120^{\circ}}{360}, \text { jika Max }=B
\end{array}\right.
$$

Where Max is Maximum value between the red, green, and blue color values. Min is a minimum value between the red, green, and blue color values. $R$ is a red color value. $G$ is a green color value. Furthermore, B is a blue color value.

The formula for calculating the Saturation value can be seen in Equation 2 [22] [23].

$$
\text { Saturation }=\left\{\begin{array}{c}
0, \text { jika Max }=0 \\
1-\frac{\text { Min }}{\operatorname{Max}}, \text { jika Max } \neq 0
\end{array}\right.
$$

The formula for calculating value can be seen in Equation 3 [22] [23].

$$
\text { Value }=\frac{\text { Max }}{255}
$$

The color moment is a representation of the value of color characteristics stored in the image. The color moment has three operations in extracting these values in the form of mean, standard deviation, and skewness [24] [25]. The mean value is the average color value of the image, the standard deviation value is the square root value of the variant, and the skewness value is the value of the degree of asymmetry. The formula for calculating the mean can be seen in Equation 4 [26]. The formula for calculating the standard deviation can be seen in Equation 5 [26]. The formula for calculating the skewness value can be seen in Equation 6 [26].

$$
\begin{aligned}
& \text { Mean }=\frac{1}{N} \sum_{N}^{j=1} P i j \\
& \text { Standard Deviation } \sqrt{\frac{1}{N} \sum_{N}^{j=1}(\text { Pij-Mean })^{2}} \\
& \text { Skewness }=\sqrt[3]{\frac{1}{N} \sum_{N}^{j=1}(\text { Pij-Mean })^{3}}
\end{aligned}
$$

Where $P_{i j}$ is the value of the $i^{\text {th }}$ color component in the $j^{\text {th }}$ pixel, and $\mathrm{N}$ is the number of pixels of the image.

\subsection{Haralick Features Extraction}

Texture features are visual patterns that show homogeneity in the image. The texture feature has essential information regarding the pattern of image structure and its relationship to the environment around the image [27]. Some techniques that can be used to extract texture features are Local Binary Pattern (LBP), Gray-level Co-occurrence Matrix (GLCM), and Haralick features [28] [29] [30].

Haralick features are one method that can be used to extract texture features from images. Haralick features use the co-occurrence matrix to store the value of texture features. Based on the research, the Haralick features have five features that can be used, namely Contrast, Correlation, Energy, Entropy, and Local Homogeneity. The five features will be calculated at degrees $0,45,90$, and 135 to create a co-occurrence matrix [31]. The formula to calculate the value of the five features can be seen in Equation 7, Equation 8, Equation 9, Equation 10, and Equation 10. 


$$
\begin{aligned}
& \text { Contrast }=\sum i \sum j(i, j)^{2} * M(i, j) \\
& \text { Correlation }=\frac{1}{\sigma i \sigma j} \sum i \sum j(i-\mu i) *(j-\mu j) * M(i, j) \\
& \text { Energy }=\sum i \sum j(M(i, j))^{2} \\
& \text { Entropy }=\sum i \sum j M(i, j) * \log (M(i, j)) \\
& \text { Local Homogenity }=\sum i \sum j \frac{M(i, j)}{1+(i-j)^{2}}
\end{aligned}
$$

\subsection{K-Nearest Neigbor}

K-nearest neighbor algorithm is one of the classification algorithms in recognizing patterns [32]. This algorithm classifies based on the class that has the lowest distance value or the highest similarity value than other classes. This algorithm has the advantage of being fast, easy to learn, robust against noise, and valid for extensive data. Meanwhile, the weakness is that this algorithm will produce low accuracy if the training data contains irrelevant values [14]. In the k-nearest neighbor method, a method is needed to determine the value of distance or similarity, such as Average Distance, Euclidean Distance, Manhattan Distance, and Maximum Distance. The formula for calculating distances in the Average Distance method can be seen in Equation 12. Moreover, the formula for calculating Average Distance, Euclidean Distance, Manhattan Distance, and Maximum Distance uses equations in Equations 12, 13, 14, and 15, respectively.

$$
\begin{aligned}
& d(x, y)=\sqrt{\frac{1}{d} * \sum_{i=1}^{d}(x i-y i)^{2}} \\
& d(x, y)=\sqrt{\sum_{i=1}^{d}(x i-y i)^{2}} \\
& d(x, y)=\sum_{i=1}^{d}|x i-y i| \\
& d(x, y)=\max _{i=1 . . d}|x i-y i|
\end{aligned}
$$

\subsection{Proposed Method}

The steps of the method to be used in this study are as follows:

1. Input the training and testing data

Data used in this study were divided into 4 classes namely, natural, replanted, soil, and river. Natural is a mangrove forest that grows naturally, replanted is a mangrove forest that grows by planting by humans, soil is an area of land, and a river is a river. Examples of data used in this study can be seen in Figure 1.

2. Extract each data value

a. Extract color values in the RGB space

b. Convert color values in the RGB to HSV space using Equation 3.1, Equation 3.2, and Equation 3.3.

c. Calculation of color moment values in the HSV color space using Equation 3.4, Equation 3.5, and Equation 3.6

d. Convert to grayscale color space

The purpose of the conversion to grayscale color space is to extract the GLCM value used to calculate the texture feature value.

e. Extraction of texture feature values in GLCM

The texture features extracted are Contrast, Correlation, Energy, Entropy, and Local Homogeneity at degrees $0,45,90$, and 135 GLCM. 

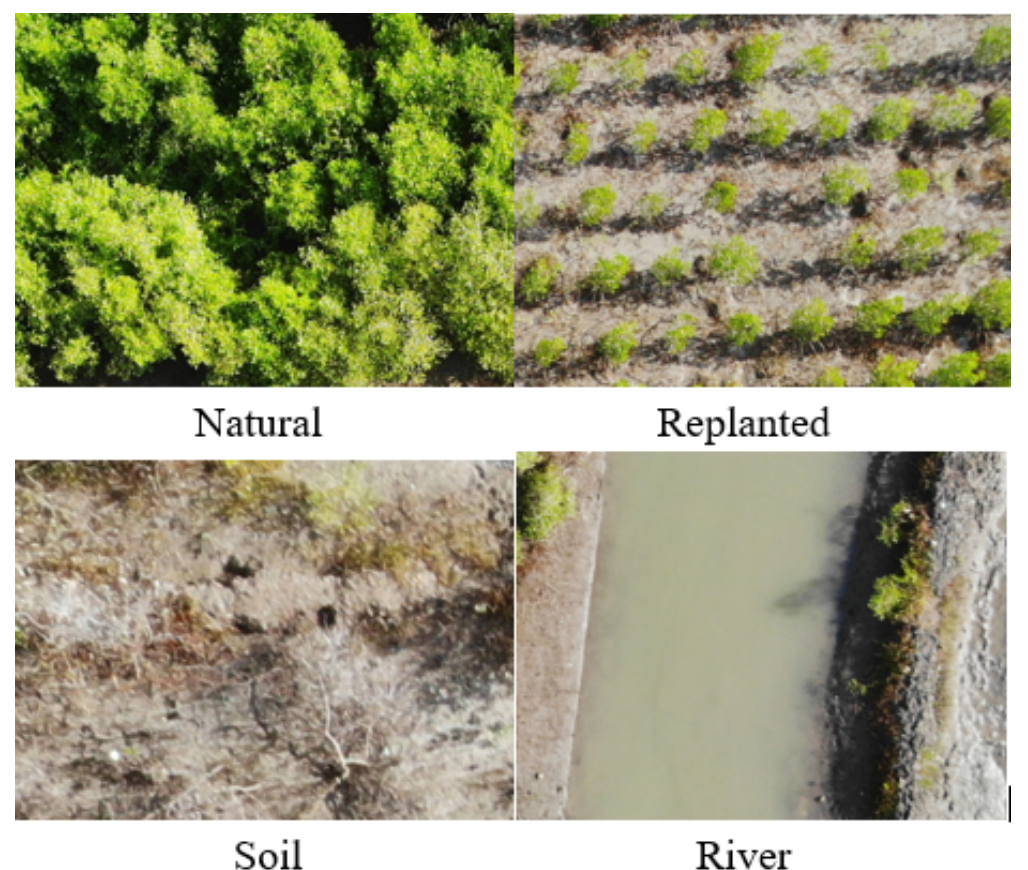

Fig. 1.Example data used in this research.

3. Classification by applying the K-Nearest Neighbor method.

The steps used above are to combine all the methods used in source research in Table 1. It is expected that by combining the methods used in the source paper, a better accuracy value is obtained in doing image classification.

\section{Results}

\subsection{Testing for Distance Methods}

Testing the accuracy of the distance method system is done using 4 scenarios:

- The first scenario is to classify K-Nearest Neighbors using the Average Distance method.

- The second scenario is to classify K-Nearest Neighbors using the Euclidean Distance method.

- The third scenario is to classify K-Nearest Neighbors using the Manhattan Distance method.

- The fourth scenario is to classify K-Nearest Neighbors using the Maximum Distance method.

The test was carried out using 20 training data and 1 test data. Each test data will be divided into 25 equal parts so that there will be 25 classifications. The k-value used in the k-nearest neighbor classification method is 3 . The results of system testing using the Average Distance method can be seen in Table 2.

Table 2. Confusion Matrix of Average Distance Method Testing

\begin{tabular}{cccccc}
\hline & \multicolumn{5}{c}{ Prediction Class } \\
\hline \multirow{4}{*}{$\begin{array}{c}\text { Original } \\
\text { Class }\end{array}$} & Natural & Replanted & Soil & River \\
\cline { 2 - 6 } & Replanted & 3 & 1 & 0 & 0 \\
\cline { 2 - 6 } & Soil & 0 & 9 & 0 & 0 \\
\cline { 2 - 6 } & River & 0 & 4 & 1 & 0 \\
\hline
\end{tabular}


Based on Table 2, the test results using the Average Distance method obtained 17 results from a total of 25 images that are classified correctly, consisting of 7 natural class images, 9 replanted class images, 1 soil class image, and 0 river class images. The accuracy of this test is $68 \%$. Table 3 shows the results of system testing using the Euclidean Distance method.

Table 3. Confusion matrix of the Euclidean Distance Method testing

\begin{tabular}{cccccc}
\hline & \multicolumn{5}{c}{ Prediction Class } \\
\hline \multirow{4}{*}{$\begin{array}{c}\text { Original } \\
\text { Class }\end{array}$} & Natural & Replanted & Soil & River \\
\cline { 2 - 6 } & Replanted & 0 & 1 & 0 & 0 \\
\cline { 2 - 6 } & Soil & 0 & 3 & 0 & 0 \\
\cline { 2 - 6 } & River & 0 & 0 & 0 & 0 \\
\hline
\end{tabular}

Based on Table 3, the test results using the Euclidean Distance method obtained 21 results from a total of 25 images that are classified correctly, consisting of 7 natural class images, 12 replanted class images, 2 soil class images, and 0 river class images. The accuracy of this test is $84 \%$. Table 4 shows the results of testing the system using the Manhattan Distance method.

Table 4. Confusion matrix of the Manhattan Distance Method Testing

\begin{tabular}{cccccc}
\hline & \multicolumn{5}{c}{ Prediction Class } \\
\hline \multirow{3}{*}{$\begin{array}{c}\text { Original } \\
\text { Class }\end{array}$} & Natural & Replanted & Soil & River \\
\cline { 2 - 6 } & Replanted & 7 & 1 & 0 & 0 \\
\cline { 2 - 6 } & Soil & 0 & 9 & 0 & 0 \\
\cline { 2 - 6 } & River & 0 & 0 & 2 & 0 \\
\hline
\end{tabular}

Based on Table 4, the results of testing using the Manhattan Distance method obtained 18 results from a total of 25 correctly classified images, consisting of 7 natural class images, 9 replanted class images, 2 soil class images, and 0 river class images. The accuracy of this test is $72 \%$. The results of testing the system using the Maximum Distance method can be seen in Table 5.

Table 5. Confusion Matrix of the Maximum Distance testing

\begin{tabular}{cccccc}
\hline & \multicolumn{5}{c}{ Prediction Class } \\
\hline \multirow{3}{*}{$\begin{array}{c}\text { Original } \\
\text { Class }\end{array}$} & Natural & Replanted & Soil & River \\
\cline { 2 - 6 } & Replanted & 7 & 1 & 0 & 0 \\
\cline { 2 - 6 } & Soil & 1 & 5 & 2 & 0 \\
\cline { 2 - 6 } & River & 0 & 3 & 0 & 1 \\
\hline
\end{tabular}

Based on Table 5, the results of testing using the Maximum Distance method obtained 12 results from a total of 25 correctly classified images, consisting of 7 natural class images, 5 replanted class images, 0 soil class images, and 0 river class images. The accuracy of this test is $48 \%$.

Based on the test results on the four tests above, we get different results between tests. The accuracy produced by the Average Distance, Euclidean Distance, Manhattan Distance, and Maximum Distance methods can be seen in Figure 2. 


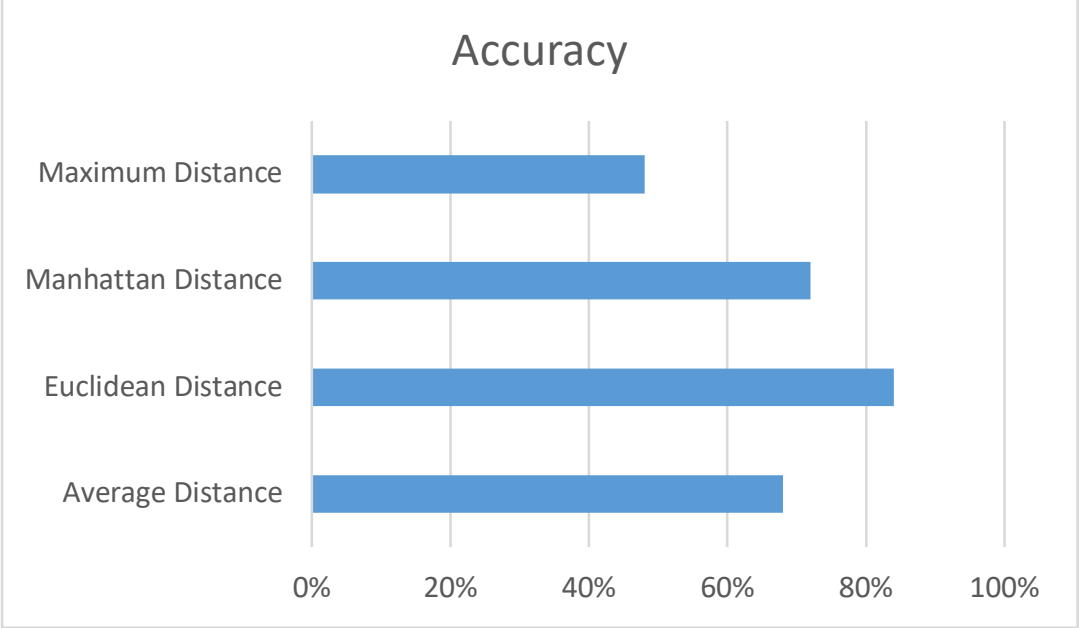

Fig. 2.Comparison of Accuracy of Distance Method

Based on the results of the system accuracy in Figure 2, it was found that the Euclidean distance method produces a higher level of accuracy compared to the Average Distance, Manhattan Distance, and Maximum Distance methods. The highest accuracy produced is $92 \%$. This test proves that the distance method used in the k-nearest neighbor classification method has an influence on the accuracy of this classification system.

\subsection{Testing for $\mathrm{K}-$ Value}

Testing the value of $\mathrm{k}$ against the accuracy of the system is done by using $\mathrm{k}$ values of $3,5,7$, and 9. The distance method used is Euclidean Distance. This test uses 20 training data and 3 test data. Each test data will be divided into 25 equal parts so there will be 75 classifications. The results of testing the system using the value $\mathrm{k}=3$ can be seen in Table 6 .

Table 6.

Confusion Matrix Testing $\mathrm{K}=3$

\begin{tabular}{cccccc}
\hline & \multicolumn{5}{c}{ Prediction Class } \\
\hline \multirow{4}{*}{$\begin{array}{c}\text { Original } \\
\text { Class }\end{array}$} & Natural & Replanted & Soil & River \\
\cline { 2 - 6 } & Replanted & 2 & 2 & 0 & 0 \\
\cline { 2 - 6 } & Soil & 0 & 37 & 2 & 0 \\
\cline { 2 - 6 } & River & 0 & 3 & 4 & 0 \\
\hline
\end{tabular}

Based on Table 6 , the results of testing using $K=3$, there were 63 of a total of 75 images classified correctly, consisting of 18 natural class images, 37 replanted class images, 4 soil class images, and 4 river class images. The accuracy of this test is $84 \%$. The results of testing the system using the value $\mathrm{k}=5$ can be seen in Table 7 .

Table 7. Confusion Matrix Testing $\mathrm{K}=5$

\begin{tabular}{cccccc}
\hline & \multicolumn{5}{c}{ Prediction Class } \\
\hline \multirow{3}{*}{$\begin{array}{c}\text { Original } \\
\text { Class }\end{array}$} & Natural & Replanted & Soil & River \\
\cline { 2 - 6 } & Replanted & 16 & 2 & 0 & 2 \\
\cline { 2 - 6 } & Soil & 0 & 33 & 2 & 3 \\
\cline { 2 - 6 } & River & 0 & 4 & 3 & 0 \\
\hline
\end{tabular}

Based on Table 7, the results of testing using $\mathrm{K}=5$, there are 55 of a total of 75 right class images, consisting of 16 natural class images, 33 replanted class images, 3 soil class images, and 3 river class 
images. The accuracy of this test is $74.67 \%$. The results of testing the system using the value $\mathrm{k}=7$ can be seen in Table 8 .

Table 8. $\quad$ Confusion Matrix Testing $\mathrm{K}=7$

\begin{tabular}{cccccc}
\hline & \multicolumn{5}{c}{ Prediction Class } \\
\hline \multirow{3}{*}{$\begin{array}{c}\text { Original } \\
\text { Class }\end{array}$} & Natural & Replanted & Soil & River \\
\cline { 2 - 6 } & Replanted & 3 & 3 & 0 & 2 \\
\cline { 2 - 6 } & Soil & 0 & 32 & 2 & 4 \\
\cline { 2 - 6 } & River & 1 & 3 & 3 & 0 \\
\hline
\end{tabular}

Based on Table 8, the results of testing using $\mathrm{K}=7$, there are 53 of a total of 75 images that are classified correctly, consisting of 15 natural class images, 32 replanted class images, 3 soil class images, and 3 river class images. The accuracy of this test is $70.67 \%$. The results of testing the system using the value $\mathrm{k}=9$ can be seen in Table 9 .

Table 9. Confusion Matrix Testing $\mathrm{K}=9$

\begin{tabular}{cccccc}
\hline & \multicolumn{5}{c}{ Prediction Class } \\
\hline \multirow{3}{*}{$\begin{array}{c}\text { Original } \\
\text { Class }\end{array}$} & Natural & Replanted & Soil & River \\
\cline { 2 - 7 } & Neplanted & 5 & 4 & 1 & 4 \\
\cline { 2 - 6 } & Soil & 0 & 30 & 3 & 3 \\
\cline { 2 - 6 } & River & 1 & 4 & 3 & 0 \\
\hline
\end{tabular}

Based on Table 9, the test results using $K=9$, there are 47 out of a total of 75 images classified correctly, consisting of 11 natural class images, 30 replanted class images, 3 soil class images, and 3 river class images. The accuracy of this test is $62.67 \%$.

Based on the test results on the four tests above, we get different results between tests. The accuracy produced by each k-value can be seen in Table 10 .

Table 10. Comparison of Accuracy of K Values

\begin{tabular}{cc}
\hline K value & Accuracy \\
\hline 3 & $84,00 \%$ \\
\hline 5 & $74,67 \%$ \\
\hline 7 & $70,67 \%$ \\
\hline 9 & $62,67 \%$ \\
\hline
\end{tabular}

Based on the results of the system accuracy in Table 10, it was found that testing with a value of $\mathrm{k}$ $=3$ resulted in a higher level of accuracy compared with a value of $\mathrm{k}=5$, a value of $\mathrm{k}=7$, and a value of $\mathrm{k}=9$. The highest accuracy produced is $84 \%$. This test proves that the value of $\mathrm{k}$ has an influence on the accuracy of this classification system.

\section{Conclusion}

Based on the testing that has been done, the following conclusions are obtained the classification system using the HSV color moment color features and Haralick feature texture features using the knearest neighbor classification method produces an accuracy of $84 \%$ using Euclidean distance with $\mathrm{k}=3$.

With a good accuracy, it is expected that this system can be used in managing mangrove forest areas in order to maintain the function of mangrove forests and avoid undesirable things, such as 
illegal logging, and others. With this system, things like that can be detected using the classification system in this study.

This research is far from perfect and there is a need for development. The suggestions for further research are there needs to be a feature selection of the features used to find out what features have a large influence on the results of the classification so that it can improve the accuracy of the classification system and further research is needed for other color spaces besides HSV, such as YUV, LBP, and others to be used as a feature of the classification system.

\section{References}

[1] N. Sahriman, A. M. Saman, M. Z. Zainal, N. Ghazali and M. A. Abbas, "Appraising Effect of Environmental Parameter Toward Mangrove Area: A Review," in 2017 IEEE 13th International Colloquium on Signal Processing \& its Applications (CSPA 2017), Penang, Malaysia, 2017.

[2] S. Chakravortty, J. Li and A. Plaza, "A Technique for Subpixel Analysis of Dynamic Mangrove Ecosystems With Time-Series Hyperspectral Image Data," IEEE Journal of Selected Topics in Applied Earth Observations and Remote Sensing, vol. 11, no. 4, pp. 1244 - 1252, 2018.

[3] W. Ohira, K. Honda and M. Nagai, "Tsunami Inundation Damping Performance of Mangrove Based on Two-Dimensional Numerical Simulation," in 2015 IEEE International Geoscience and Remote Sensing Symposium (IGARSS), Milan, Italy, 2015.

[4] N. T. Son, C. F. Chen, N. B. Chang, C. R. Chen, L. Y. Chang and B. X. Thanh, "Mangrove Mapping and Change Detection in Ca Mau Peninsula, Vietnam, Using Landsat Data and Object-Based Image Analysis," IEEE Journal of Selected Topics in Applied Earth Observations and Remote Sensing, pp. 503$510,2015$.

[5] R. B. Thapa, M. Watanabe, T. Motohka, T. Shiraishi and M. Shimada, "Calibration of Aboveground Forest Carbon Stock Models for Major Tropical Forests in Central Sumatra Using Airborne LiDAR and Field Measurement Data," IEEE Journal of Selected Topics in Applied Earth Observations and Remote Sensing, vol. 8, no. 2, pp. $661-673,2015$.

[6] G. Metternicht, R. Lucas, P. Bunting, A. Held, L. Lymburner and C. Ticehurst, "Addressing Mangrove Protection in Australia: The Contribution of Earth Observation Technologies," in IGARSS 2018 - 2018 IEEE International Geoscience and Remote Sensing Symposium, Valencia, Spain, 2018.

[7] L. Moreno, V. Ramos, M. Pohl and F. Huguet, "Comparative Study of Multispectral Satellite Images and RGB Images Taken from Drones for Vegetation Cover Estimation," in 2018 IEEE 38th Central America and Panama Convention (CONCAPAN XXXVIII), San Salvador, El Salvador, 2018.

[8] L. Faramondi, G. Oliva, L. Ardito, A. Crescenzi, M. Caricato, M. Tesei, A. O. Muda and R. Setola, "Use of Drone to Improve Healthcare Efficiency and Sustainability," in MIPRO 2019 - 42nd International Convention, Opatjia, Croatia, 2019.

[9] A. N. Ganar, C. S. Gode and S. M. Jambhulkar, "Enhancement of Image Retrieval by Using Colour, Texture and Shape Features," in 2014 International Conference on Electronic Systems, Signal Processing and Computing Technologies, Nagpur, India, 2014.

[10] N. Singh, S. R. Dubey, P. Dixit and J. P. Gupta, "Semantic Image Retrieval by Combining Color, Texture and Shape Features," in 2012 International Conference on Computing Sciences, Phagwara, India, 2012.

[11] D. Pratiwi, E. T. Lussiana and S. Madenda, "Image Color Extraction of Forest," SINTA - Science and Technology Index, pp. 287-407, 2013.

[12] A. Bekkari, D. Mammas, S. Idbraim and A. Elhassouny, "SVM and Haralick Features for Classification of High Resolution Satellite Images from Urban Areas," in Proceedings of the 5th international conference on Image and Signal Processing, Berlin, Heidelberg, 2012. 
[13] G. Taskin, H. Kaya and L. Bruzzone, "Feature Selection Based on High Dimensional Model Representation for Hyperspectral Images," IEEE, vol. 26, pp. 2918-2928, 24 March 2017.

[14] N. Bhatia and Vandana, "Survey of Nearest Neighbor Techniques," International Journal of Computer Science and Information Security, vol. 8, no. 2, pp. 302-305, 2010.

[15] W. Lumchanow and S. Udomsiri, "Combination of GLCM and KNN Classification for Chicken Embryo Development Recognition," in 2019 Joint International Conference on Digital Arts, Media and Technology with ECTI Northern Section Conference on Electrical, Electronics, Computer and Telecommunications Engineering (ECTI DAMT-NCON), Nan, Thailand, 2019.

[16] M. Mosbah and B. Boucheham, "The Influence of The Color Model on The Performance of a CBIR System Based on Color Moments," Journal of Communication and Computer, vol. 11, no. 3, pp. 266273, 2014.

[17] S. Simonthomas, P. Asharaf and N. Thulasi, "Automated Diagnosis of Glaucoma using Haralick Texture Features," in International Conference on Information Communication and Embedded Systems (ICICES2014), Chennai, India , 2014.

[18] M. Loesdau, S. Chabrier and A. Gabillon, "Hue and Saturation in the RGB Color Space," in ICISP 2014, Cherbourg, France, 2014.

[19] A. Ajmal, C. Hollitt, M. Frean and H. A. Sahaf, "A Comparison of RGB and HSV Colour Spaces for Visual Attention Models," in 2018 International Conference on Image and Vision Computing New Zealand (IVCNZ), Auckland, New Zealand, 2018.

[20] M. Kunaver and J. F. Tasic, "Image Feature Extraction - an overview," in EUROCON 2005, Belgrade, Serbia, 2005.

[21] J. Mazumder, L. N. Nahar and M. U. Atique, "Finger Gesture Detection and Application Using Hue Saturation Value," International Journal of Image, Graphics and Signal Processing, pp. 31-38, 8 August 2018.

[22] L. Feng, L. Xiaoyu and C. Yi, "An Efficient Detection Method for Rare Colored Capsule Based on RGB and HSV Color Space," in 2014 IEEE International Conference on Granular Computing ( $\mathrm{GrC})$, Noboribetsu, Japan, 2014.

[23] D. S. Y. Kartika and D. Herumurti, "Koi Fish Classification Based on HSV Color Space," in 2016 International Conference on Information \& Communication Technology and Systems (ICTS), Surabaya, Indonesia, 2016.

[24] T. Weng, Y. Yuan, L. Shen and Y. Zhao, "Clothing Image Retrieval Using Color Moment," in Proceedings of 2013 3rd International Conference on Computer Science and Network Technology, Dalian, China, 2013.

[25] E. Juliastuti, V. Nadhira, Y. W. Satwika, N. A. Aziz and N. Zahra, "Risk Zone Estimation of Newborn Jaundice Based on Skin Color Image Analysis," in 2019 6th International Conference on Instrumentation, Control, and Automation (ICA), Bandung, Indonesia, 2019.

[26] R. Roslan, N. A. Nazery , N. Jamil and R. Hamzah, "Color-Based Bird Image Classification using Support Vector Machine," in 2017 IEEE 6th Global Conference on Consumer Electronics (GCCE), Nagoya, Japan, 2017.

[27] M. B. Valentin, C. R. Bom, M. P. Albuquerque, E. L. Faria and M. D. Correia, "Texture Classification Based on Spectral Analysis and Haralick Features," CBPF, vol. 6, pp. 28-61, 1 April 2016. 
[28] A. Bekkari, S. Idbraim, D. Mammas and M. E. Yassa, "Exploiting Spectral and Space Information in Classification of High Resolution Urban Satellites Images using Haralick Features and SVM," in 2011 International Conference on Multimedia Computing and Systems, Ouarzazate, Morocco, 2011.

[29] G. Mukherjee, A. Chatterjee and B. Tudu, "Study on The Potential of Combined GLCM Features towards Medicinal Plant Classification," in 2016 2nd International Conference on Control, Instrumentation, Energy \& Communication (CIEC), Kolkata, India, 2016.

[30] Y. He, N. Sang and R. Huang, "Local Binary Pattern Histogram based Texton Learning for Texture Classification," in 2011 18th IEEE International Conference on Image Processing, Brussels, Belgium, 2011.

[31] R. Subban, N. Susitha and D. P. Mankame, "Efficient Iris Recognition using Haralick Features Based Extraction and Fuzzy Particle Swarm Optimization," Cluster Computing, vol. 21, no. 1, pp. 79-90, March 2018.

[32] R. F. Rahmat, T. Aruan, S. Purnawati, S. Faza, T. Z. Lini and Onrizal, "Fungus Image Identification using K-Nearest Neighbor," in IOP Conference Series Materials Science and Engineering, Medan, Sumatera Utara, 2018. 